\title{
The 60th anniversary of Japanese primatology
}

\author{
Toshisada Nishida
}

Published online: 10 January 2009

(C) Japan Monkey Centre and Springer 2009

Japanese primatology is considered to have begun in December 1948, when Kinji Imanishi (then 46 years old), Shunzo Kawamura (24 years old), and Junichiro Itani (22 years old) visited Koshima Island to look into the possibility of conducting a field study of Japanese monkeys there. Kawamura and Itani were already impressed by the well-organized procession of monkeys they had observed at Cape Toimisaki the previous month when they were observing semi-wild horses as Imanishi's assistants (Itani 1991; Kawai 2007). As Imanishi had already read through Carpenter's pioneering studies, his change of study targets from horses to macaques was not according to the mood of the moment. This was a case in which Fortune knocks on the door of the person who is prepared for it (Nishida 2007).

Since this epoch-making survey of Japanese monkeys in the natural habitat of southern Japan, 60 years have passed, and we celebrated the 60th anniversary of Japanese primatology last year. During this period, Japanese primatology gradually took shape as it passed several milestones, such as the establishment of the Japan Monkey Centre in 1956, the Laboratory of Physical Anthropology at Kyoto University in 1962, the Kyoto University Primate Research Institute in 1966, the Tsukuba Primate Research Center in 1978, and the Primate Society of Japan in 1985.

The first issue of Primates appeared in 1957, 5 years earlier than the second primate journal, Folia Primatologica. However, owing to its irregular publication in the earliest period, producing only one volume in 2 years, vol. 50 appears this year, in 2009. Consequently, vol. 50 of

T. Nishida $(\square)$

Japan Monkey Centre, Inuyama, Japan

e-mail: nishida@jinrui.zool.kyoto-u.ac.jp
Primates is publishing special contributions in the first and second issues.

Primates has published many momentous papers, including those on the proposal to study primate culture, the initiation of wild gorilla research, and primate politics (vol. 1); the importance of kin relationships in organizing primate societies and the first detailed study of primate vocalizations (vol. 4); the first documentation of primate cultural transmission and the discovery of infanticide (vol. 6); discoveries of chimpanzee (vol. 9) and bonobo (vols. 20 and 23) social units; and a contribution to the social brain hypothesis (vol. 31).

As one of the events to commemorate the 60th anniversary, the associate editors based in Japan gathered at Inuyama in the summer of 2007 to discuss the special publication of Primates.

Because the special issue on Japanese macaque studies had been published not long before (vol. 39), we decided to collect reviews on recently developed studies based on the editors' recommendations. Regrettably, some candidates could not comply with our request because of the tight publishing schedule. However, 11 authors eventually accepted our invitations, and we are pleased to announce that we will feature the first three papers in this issue. Eight papers will appear in the next issue, to be published in April.

In 2002, the editorial board of Primates was reorganized into associate editors and an advisory board, whose members have increased both in number and in international representation. In 2003, Springer began publishing Primates with the financial support of the Japan Monkey Centre and the Primate Society of Japan. These two changes strengthened the reviewing power of the journal (three referees ordinarily review original articles and one referee reviews short communications, in 
addition to the supervision of associate editors and the editor-in-chief) and accelerated the editorial process. Many papers are now published online within 6 months of initial submission. We also began encouraging primatologists to submit interesting papers to Primates by establishing the Primates Most-cited Paper Award in 2007.

We humbly request your continued support of this oldest of primate journals.

\section{References}

Itani J (1991) Monkeys, humans and Africa: my curriculum vitae (in Japanese). Nihon-Keizai-Shinbunsha, Tokyo

Kawai M (2007) A sketch of the dawn of Japanese primatology. In: Ohta I, Sawachika T, Terashima H, Yamagiwa J (eds) Collection of Junichiro Itani's works (in Japanese). Kodansha, Tokyo, pp 504-513

Nishida T (2007) Primatology: an international contribution to science from Japan. In: Mouri H, Yasugi S (eds) The history of zoology in Japan (in Japanese). Baifukan, Tokyo, pp 176-197 